\title{
Epónimos en la anatomía y radiología de cabeza y cuello
}

\section{Eponyms in Head and Neck Anatomy and Radiology} \author{
Luis Ariel Miquelini ${ }^{1,3, *}$ Suresh K. Mukherji ${ }^{5}$ \\ ${ }^{1}$ Servicio de Diagnóstico por Imágenes, Hospital Británico, Ciudad \\ Autónoma de Buenos Aires, Argentina \\ 2 Departamento de Diagnóstico por Imágenes, Instituto de \\ Investigaciones Neurológicas Dr. Raúl Carrea (FLENI), Ciudad \\ Autónoma de Buenos Aires, Argentina \\ ${ }^{3}$ Servicio de Diagnóstico por Imágenes, Hospital Italiano de Buenos \\ Aires, Ciudad Autónoma de Buenos Aires, Argentina \\ ${ }^{4}$ Servicio de Resonancia Magnética y Tomografía Computada, Centro \\ Médico Deragopyan, Ciudad Autónoma de Buenos Aires, Argentina \\ ${ }^{5}$ Departamento de Radiología, Universidad Estatal de Michigan, East \\ Lansing, Michigan, EEUU
}

Fernando Martín Ferraro ${ }^{1, *}$ Hernán Chaves ${ }^{2, *}$ Federico Martín Olivera Plata ${ }^{3,4, *}$

\begin{abstract}
Address for correspondence Hernán Chaves, MD, Departamento de Diagnóstico por Imágenes, Instituto de Investigaciones Neurológicas Dr. Raúl Carrea (FLENI), Montañeses 2325, C1428AQK, CABA, Argentina (e-mail: chaves.hernan@gmail.com).
\end{abstract}

Rev Argent Radiol 2018;82:72-82.

\section{Resumen \\ Palabras Clave \\ - radiología \\ - epónimos \\ - anatomía \\ - cabeza y cuello \\ - historia de la medicina}

En el lenguaje médico, el uso de epónimos es frecuente. Si bien comúnmente se piensa que los epónimos están en vías de extinción, eso no es totalmente cierto. Existe disenso entre quienes creen que su uso debería abandonarse y quienes abogan que los epónimos convierten términos inmemorables en memorizables, transmiten conceptos complejos y promueven el interés en la historia de la Medicina. Nos sentimos parte de ese segundo grupo y nuestra intención es hacer una revisión de ocho epónimos vinculados a la Anatomía y Radiología de cabeza y cuello. Creemos que ese abordaje puede ser útil para la educación de estudiantes de Medicina, residentes y especialistas en diagnóstico por imágenes.

The use of eponyms in medical language is frequent. While it is commonly thought that eponyms are on their way to extinction, this is not entirely true. There is dissent between those who believe that their use should be abandoned and those who advocate that eponyms make unmemorable terms memorable, convey complex concepts and promote interest in the history of medicine. We feel part of this second group, and our intention is to make a review of eight eponyms linked to head and neck anatomy and radiology. We believe that this approach can be useful for the education of medical students, residents and diagnostic imaging specialists.

\footnotetext{
*apítulo Multidisciplinario de Cabeza y Cuello, Sociedad Argentina de Radiología.
}

received

June 28, 2017

accepted

March 28, 2018

published online

May 11, 2018
DOI https://doi.org/

$10.1055 / \mathrm{s}-0038-1648235$.

ISSN 1852-9992.
Copyright ( 2 2019, Sociedad Argentina de Radiología. Publicado por Thieme Revinter Publicações Ltda., Rio de Janeiro, Brazil. Todos los derechos reservados.
License terms

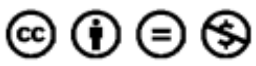




\section{Introducción}

Al buscar la palabra epónimo en el diccionario de la Real Academia Española encontramos la siguiente definición: "Dicho de una persona o de una cosa: que tiene un nombre con el que se pasa a denominar un pueblo, una ciudad, una enfermedad, etc." 1

En el lenguaje médico, el uso de epónimos es frecuente. Históricamente se han utilizado los apellidos de médicos reconocidos para hacer referencia a estructuras anatómicas, enfermedades y síndromes, habitualmente como una forma de homenaje. $^{2}$

Si bien comúnmente se piensa que los epónimos en la Medicina están en vías de extinción, eso no es totalmente cierto y su uso está presente en el $2 \%$ de los títulos de las publicaciones en la actualidad. ${ }^{3}$ Existe disenso entre quienes creen que su uso debería abandonarse y quienes abogan que los epónimos convierten términos inmemorables en memorizables, transmiten conceptos complejos y promueven el interés en la Historia de la Medicina. ${ }^{4-7}$

Nos sentimos parte de ese segundo grupo, y nuestra intención es hacer una revisión de ocho epónimos vinculados a la Anatomía y Radiología de cabeza y cuello, haciendo hincapié en mayor medida, en los artículos originales y escenarios que determinaron el surgimiento de los mismos y, en menor medida, en estructuras y patologías por las cuales los conocemos. Se ilustran mediante figuras de disecciones, imágenes radiológicas y fotografías. Creemos que ese abordaje puede ser útil para la educación de estudiantes de Medicina, residentes y especialistas en diagnóstico por imágenes.

\section{Johann Christian Rosenmüller (1771-1820)}

Johann Christian Rosenmüller (-Fig. 1) nació el 25 de mayo de 1771 en Hildburghausen, Alemania. Su padre, Johann Georg Rosenmüller, era un conocido teólogo protestante. Su hermano

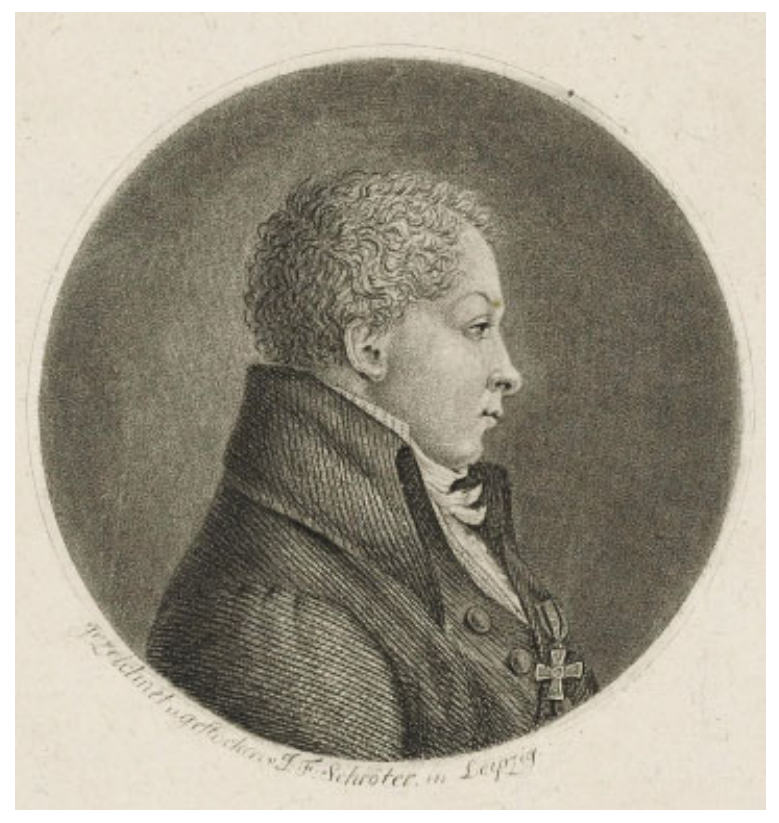

Fig. 1 Retrato de Johann Christian Rosenmüller.

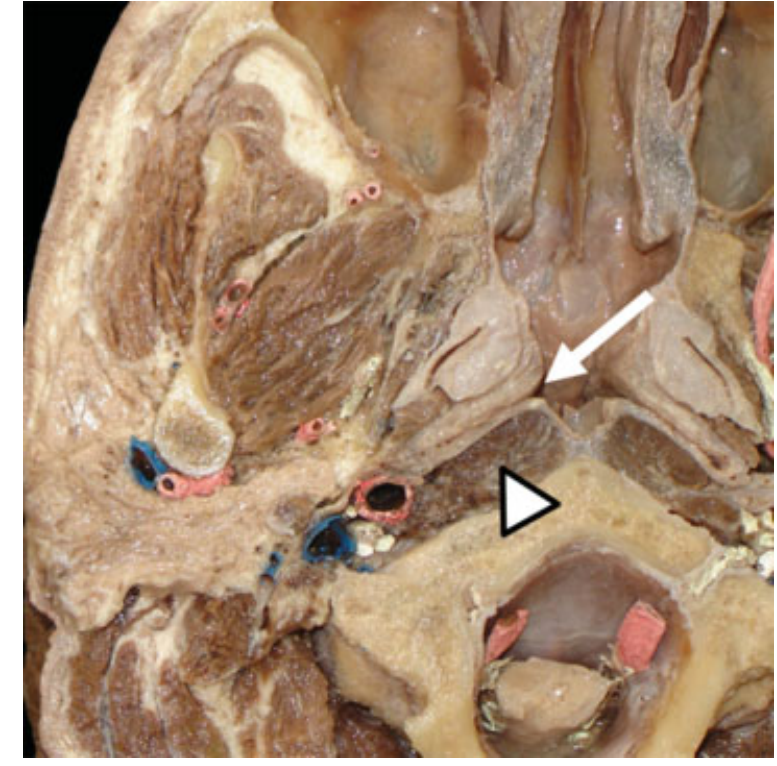

Fig. 2 Preparado anatómico con tinciones de arterias en rojo y venas en azul. Se señala a la fosa de Rosenmüller derecha (flecha), ubicada inmediatamente por delante del músculo largo del cuello (cabeza de flecha). Reimpreso con el permiso del editor. Copyright@ 2016 Fronteras de Medicina. Todos los derechos reservados.

Ernst Friedrich Karl Rosenmüller, siguió los pasos de su padre y fue muy reconocido. Los tres coincidieron en su estancia en la Universidad de Leipzig desde 1794 hasta su muerte. No se menciona nada sobre su madre en la bibliografía revisada.

En 1792 comenzó sus estudios de Medicina en la Universidad de Erlangen, doctorándose en 1797 en la Universidad de Leipzig y fue nombrado profesor asociado de Anatomía y Cirugía en Leipzig en 1802. Fue decano de dicha casa de estudios entre 1812 y 1820 . Fue autor de diversas disertaciones, artículos y libros. Sin embargo, su obra de mayor importancia fue un manual de Anatomía publicado en $1808 .^{9}$ Con una extensión de 700 páginas, abarcaba diversas áreas del cuerpo humano. Aquí es donde Rosenmüller describió por primera vez al receso faríngeo o fosa de Rosenmüller (-Figs. 2 y 3). Describió también en ese tratado, la porción palpebral de la glándula lacrimal o glándula de Rosenmüller y al órgano de Rosenmüller, una estructura del mesosalpinx.

Rosenmüller también era especialista en espeleología, el estudio científico de las cuevas, incluyendo su formación, estructura y seres vivos que las habitan. En 1796, publicó un libro en el que describía cuevas remarcables del área de Muggendorf, incluyendo la que actualmente es conocida como cueva de Rosenmüller, pudiendo ser visitada en la actualidad. Su colección de huesos fósiles reside en el museo de ciencias naturales de Berlín. Nunca se casó y murió luego de un ataque cardíaco a la edad de 49 años.

\section{Charles Bell (1774-1842) ${ }^{10}$}

Charles Bell ( - Fig. 4) es recordado como un neurofisiólogo. Sin embargo, fue un hombre de múltiples talentos: anatomista, dibujante, escritor, conferencista, cirujano y 


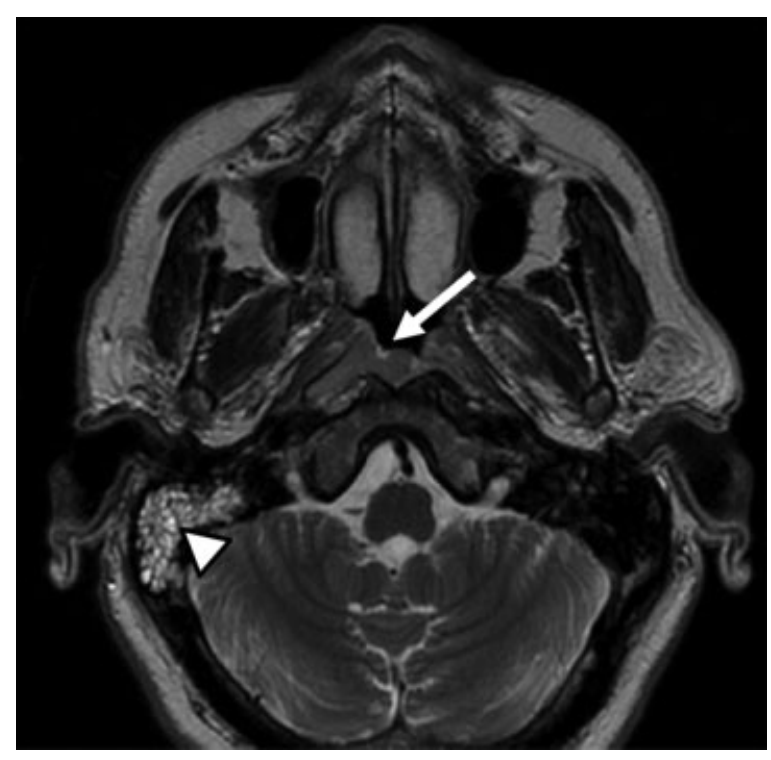

Fig. 3 Corte axial de resonancia magnética (RM) en imágenes ponderadas en T2. Paciente que consultó por sensación de oído derecho tapado e hipoacusia. Se observó una lesión que ocupaba y obstruía la fosa de Rosenmüller derecha (flecha) asociada a otitis serosa homolateral (cabeza de flecha). La lesión correspondió a un carcinoma escamoso de nasofaringe.

constructor de museos. Nació en 1774, cuarto hijo de un clérigo de Edimburgo, quien falleció cuando Charles tenía tan solo cinco años. Su madre no sólo se encargó de su crianza, sino que estimuló sus otras aptitudes como el dibujo.

Asistió a clases de Filosofía mientras ayudaba a su hermano John en la escuela de Anatomía. Contribuyó con textos e ilustraciones en la obra de su hermano "La Anatomía del Cuerpo Humano" y publicó bajo su nombre la obra titulada “Un Sistema de Disecciones" en 1814. Bell tenía

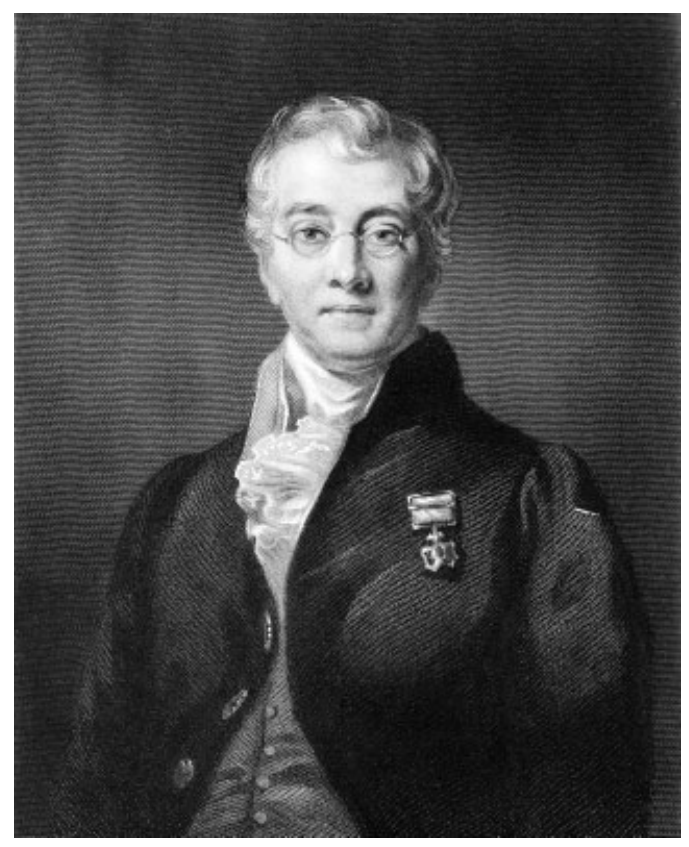

Fig. 4 Retrato de Charles Bell. Reimpreso con el permiso del editor. Copyright@ 2016 Fronteras de Medicina. Todos los derechos reservados.

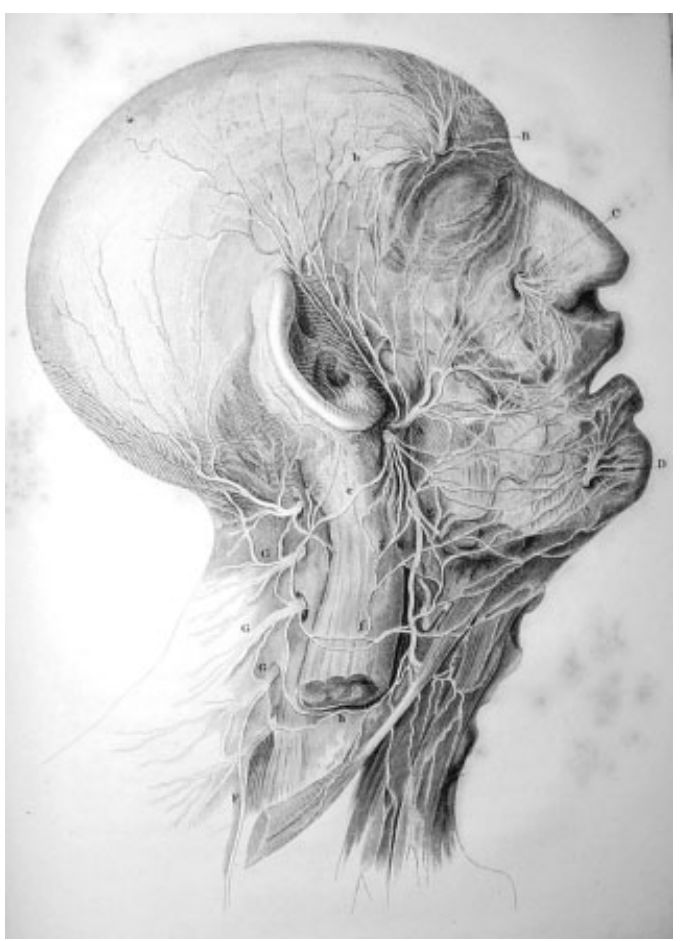

Fig. 5 Ilustración proveniente del artículo original de Charles Bell de 1821 donde se encuentra la descripción de los nervios de la cara y en particular el nervio facial.

especial interés por el quinto y séptimo nervios craneales, ya que no podía diferenciar claramente sus funciones. Dicha diferenciación fue clarificada por su colega Herbert Mayo. La descripción original de Bell de la parálisis facial en una carta enviada a un colega no puede ser más precisa. “...la cara se encuentra hacia la derecha. El ala de la nariz no se mueve en la respiración. El párpado del lado izquierdo no se cierra al intentar guiñar el ojo, sin embargo, su globo ocular gira hacia arriba. Su mejilla izquierda está relajada y su frente izquierda no presenta arrugas..."

La descripción original de la parálisis de Charles Bell, fue realizada en dos pacientes con disfunción irreversible del nervio facial: una infección severa y una secuela postquirúrgica de un tumor de base de cráneo resecado por el propio Bell. Esa descripción está incluida en la publicación titulada: "On the nerves; giving an account of some experiments on their structure and functions, which lead to a new arrangement of the system" un clásico de la neurología, publicado en Philosophical Transactions en 1821 (-Figs. 5 y 6). ${ }^{11}$ Ese concepto difiere de la definición moderna de parálisis de Bell, la cual es reversible e idiopática (-Fig. 7). Murió repentinamente el 29 de abril de 1842.

\section{Primo Dorello (1872-1963) 7,12}

Primo Dorello (-Fig. 8) nació en Narni, Italia en 1872. Estudió Medicina en la Universidad de Roma, obteniendo su diploma en 1897. Permaneció en dicha casa de estudios como profesor adjunto en el Departamento de Anatomía Humana Normal. Publicó en 1903 su artículo más conocido 


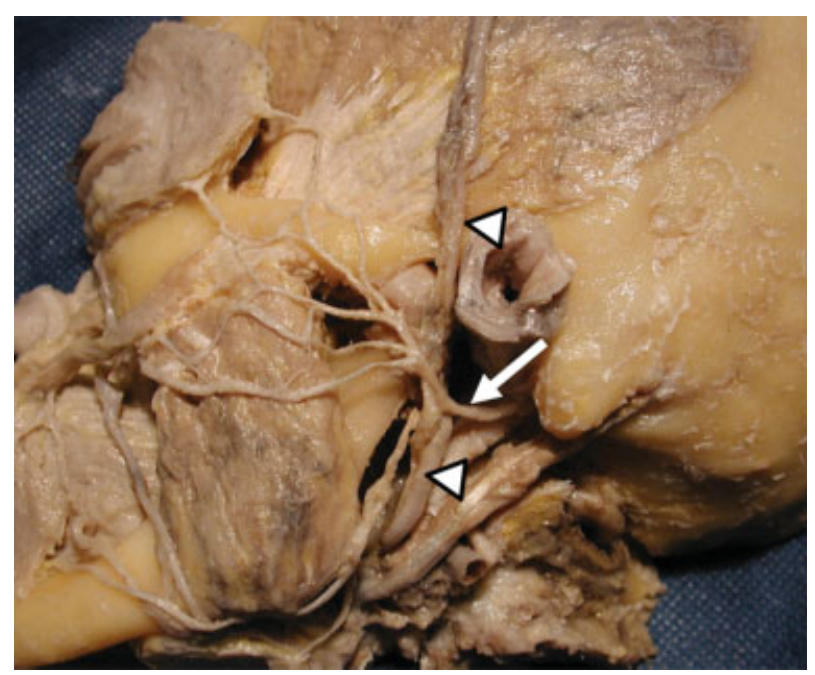

Fig. 6 Preparado anatómico de una hemicara izquierda donde se muestra al segmento extracraneal del nervio facial (flecha), cruzando a la arteria temporal superficial (cabeza de flecha).

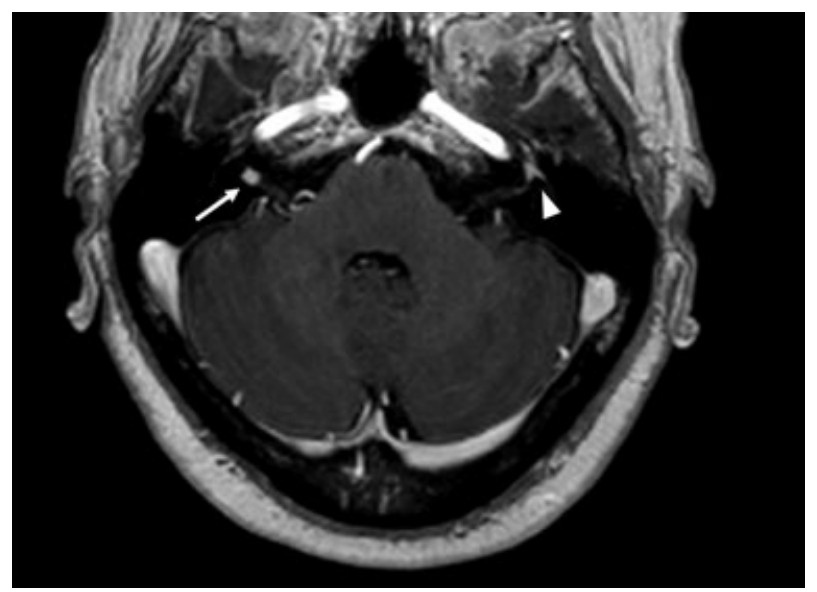

Fig. 7 Corte axial de RM en imágenes ponderadas en T1 postcontraste. Paciente que consultó por caída de la comisura labial izquierda e hipoacusia derecha. Se identificó refuerzo post-contraste de los segmentos del nervio facial canalicular, laberíntico, ganglio geniculado y timpánico izquierdos, patognomónicos de la parálisis facial idiopática (o parálisis de Bell). En el conducto auditivo interno derecho, se observó una lesión focal redondeada hiperintensa compatible con schwannoma del nervio vestibular, principal diagnóstico diferencial de la parálisis de Bell.

titulado "Consideraciones sobre la causa de la parálisis transitoria del abducens en la flogosis del oído medio" (-Fig. 9). ${ }^{13}$ El manuscrito describe al canal de Dorello, una depresión delimitada lateralmente por el ápice petroso y medialmente por la porción superolateral del clivus. El margen superior del canal está formado por el ligamento petroesfenoidal (-Figs. 10 y 11). Aunque se le dio el crédito del descubrimiento de ese canal, la primera descripción del mismo fue realizada por Wenzel Gruber en 1859, quien es recordado con el epónimo de ligamento de Gruber o petroesfenoidal. ${ }^{14}$

En las últimas décadas, diversos estudios de Anatomía microquirúrgica han dado mayor precisión a la descripción

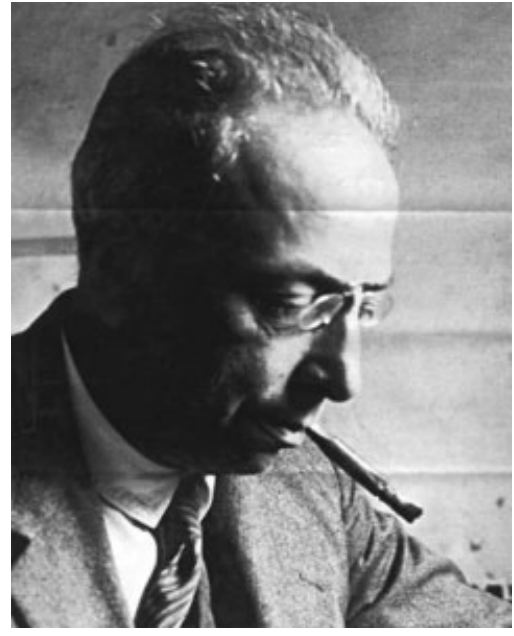

Fig. 8 Retrato de Primo Dorello.

\section{Considerazioni}

sopra In eausa della paralisi tranyitoria dell'abducente nelle flogosl dell'orecehie medio

\section{Prof. PRIM0 DORELI/0}

Già da molto tempo è noto che aleune malattie delloreo. chio medio e delfinterno hanno la loro riperenssione sulla funxionalità dei muscoli ocnlari e speofalmente sul retto esterno, sicohè non d̀ raro, in seguito at affoxioni dell'orecehio medio di un lato, avere paralis dollrabdncens dello stesso lato.

Una eaposizione pressochè completa della letterutura di questa complieazione dell'otite media si pù̀ trovare nel la. vori su tale argomento di Gradenigo.

$\mathrm{Ma}$ se sulla costatazione del fatto non vi o certo questione, vive controversie invece sorgono quando si vuole spiegare il meceanistno col quale si prodace tale complieaxione.

Volendo dare una elassifleazlone di tatte le opinioni emesse per spiegare il fenomeno, se ne potrebbero fare due categorie ed ascrivere ad una categoria tutte quelle ehe ritengono la paralisi di origine centrale, all'altm tatte quelle ele la ritengono di origine periferica.

Tra quelli ebe sostengoto l'origine periferies della panalisi dell'abducens ricordo prima dt ogni altao Gradenigo, il quale, dopo essersi occupato con speciale competenza delPargonento, sostenne ele la paralisi periferica del $6^{*}$ paio en in queati casi dovnta a focolai limitati di leptomeningite, sia purulenta, sia sierosa, propapatad dal processo flogistico dells cassa del timpano. Ricordo pol Mongardi e Citelli.

16

Fig. 9 Artículo original de Primo Dorello.

de los límites y contenidos de esa topografía conocida como confluencia venosa petroclival, que incluye al canal o, más precisamente, conducto de Dorello. ${ }^{15}$ Dorello fue nominado al premio Nobel en Medicina o Fisiología en 1939. También se interesó en Antropología y Fotografía. Produjo negativos estereoscópicos en vidrio de la arquitectura y paisajes urbanos de Italia. Falleció en Bolonia a los 90 años. 


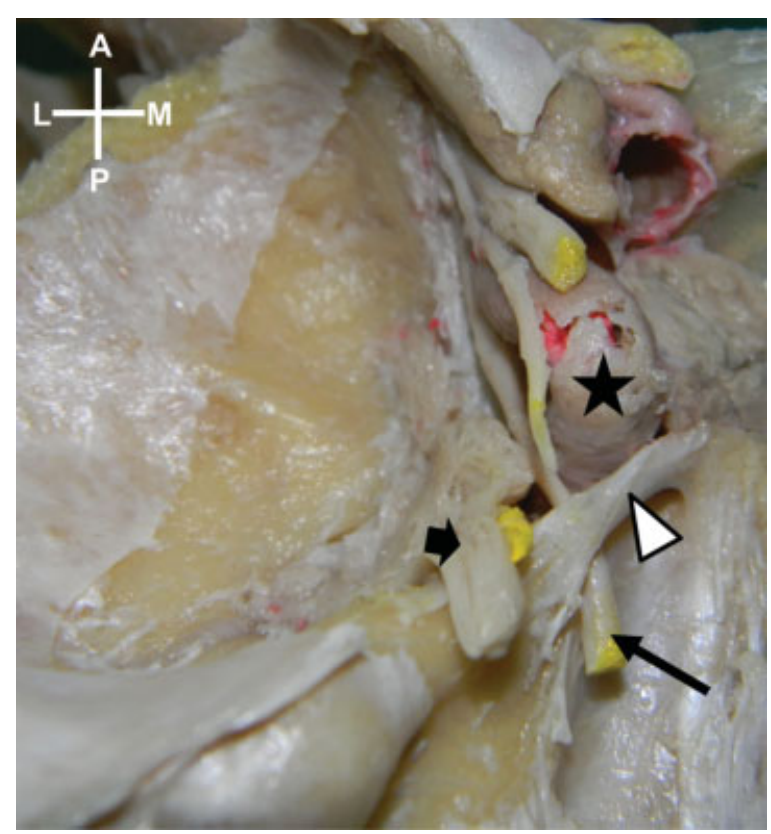

Fig. 10 Preparado anatómico, vista posterior de la región petroclinoidea izquierda, donde se observa el nervio abducens (flecha larga), atravesando el canal de Dorello. Se remarcan el ligamento petroclinoideo (cabeza de flecha), el nervio trigémino (flecha corta) y arteria carótida interna (estrella).Reimpreso con el permiso del editor. Copyright@ 2016 Fronteras de Medicina. Todos los derechos reservados.

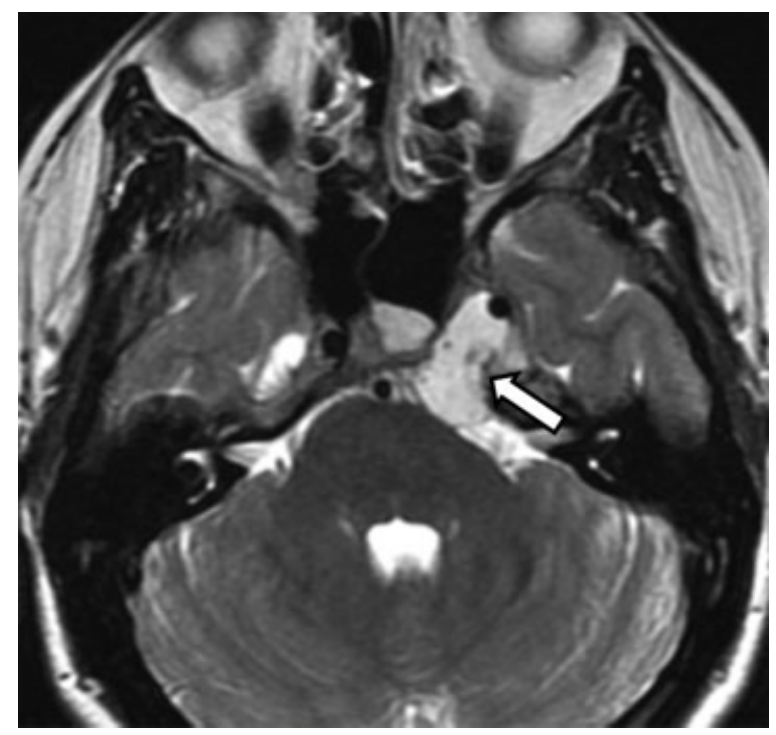

Fig. 11 Corte axial de RM en imágenes ponderadas en T2. Paciente que consultó por parálisis del sexto nervio craneal izquierdo e hipoestesia facial ipsilateral. Se observó una lesión que compromete la región petroclival izquierda (flecha), la cual es marcadamente hiperintensa en imágenes ponderadas en T2 (probable componente cartilaginoso). Correspondió a un condrosarcoma. Reimpreso con el permiso del editor. Copyright@ 2016 Fronteras de Medicina. Todos los derechos reservados.

\section{Carlo Mondini (1729-1803) ${ }^{16}$}

Carlo Mondini (-Fig. 12) fue un anatomista y médico italiano. Nació en Bolonia, Italia en 1729. Se graduó en Filosofía y Medicina de la Universidad de Bolonia en 1757.

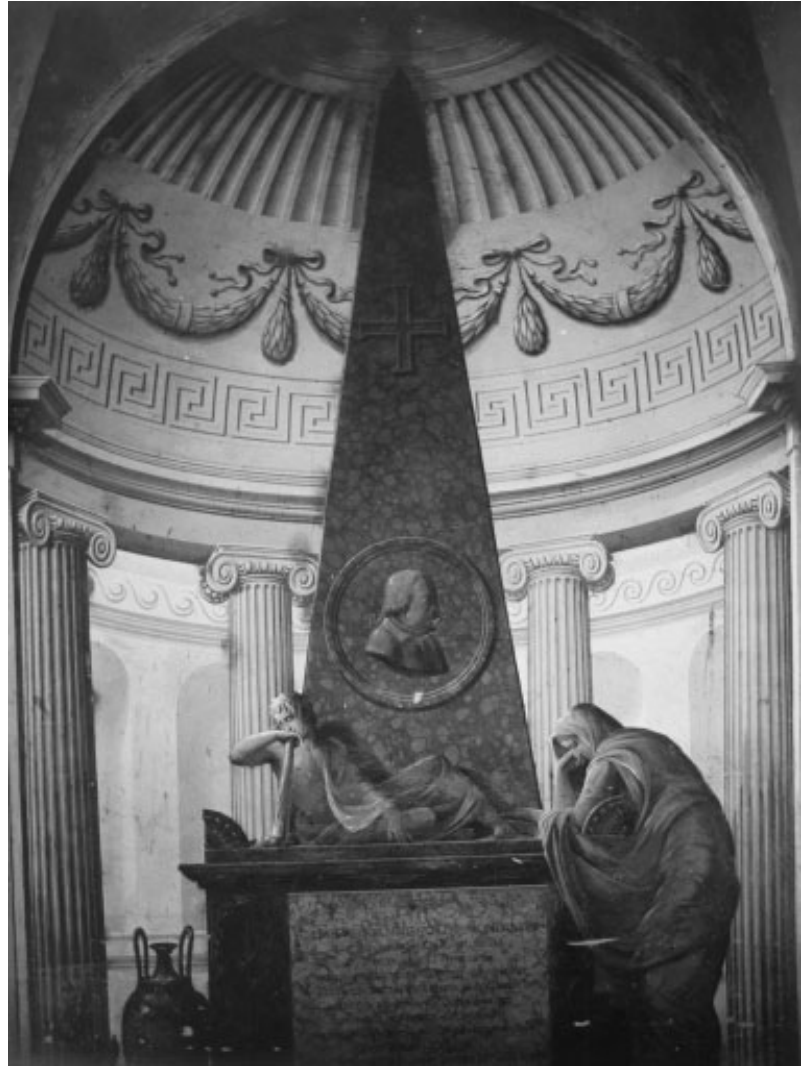

Fig. 12 Sepulcro de Carlo Mondini y familia en el Cementerio Monumental de La Cartuja de Bolonia.

Es en esa casa de estudios donde obtuvo su primer cargo como profesor, estuvo a cargo de disecciones anatómicas y eventualmente se convirtió en Jefe de Departamento.

Trabajó con gran dedicación en las malformaciones de los oídos, especialmente en la morfología de la cóclea. Fue él también quien identificó y describió los ovarios por primera vez.

Tuvo doce hijos, de los cuales Francesco, fue quien continuó sus estudios anatómicos. Murió en 1803 a la edad de 74 años. Describió la malformación de Mondini por primera vez en un niño de 8 años con sordera congénita fallecido por sepsis luego de un accidente. Mondini conocía al niño, por lo que realizó la disección del hueso temporal (-Figs. 13 y 14). ${ }^{17}$ Describió la malformación de la cóclea, de un giro y medio con un modiolo deformado. También describió un acueducto vestibular y vestíbulo aumentados de tamaño (-Fig. 15), malformaciones que también se pueden observar en el síndrome del acueducto vestibular dilatado.

\section{Wilhelm Waldeyer (1836-1921) ${ }^{18}$}

Heinrich Wilhelm Gottfried Waldeyer ( - Fig. 16) nació el 6 de octubre de 1836 en Hehlen, un pequeño pueblo, en el reino de Prusia. Se casó y tuvo cuatro hijos. Luego de presenciar una conferencia del famoso anatomista Jakob Henle, se decidió a seguir esa profesión por lo que comenzó sus estudios médicos, graduándose en 1862 en Berlín.

Fue nombrado Profesor Titular de Anatomía Patológica en 1867. Waldeyer publicó 269 trabajos a lo largo de su carrera, 


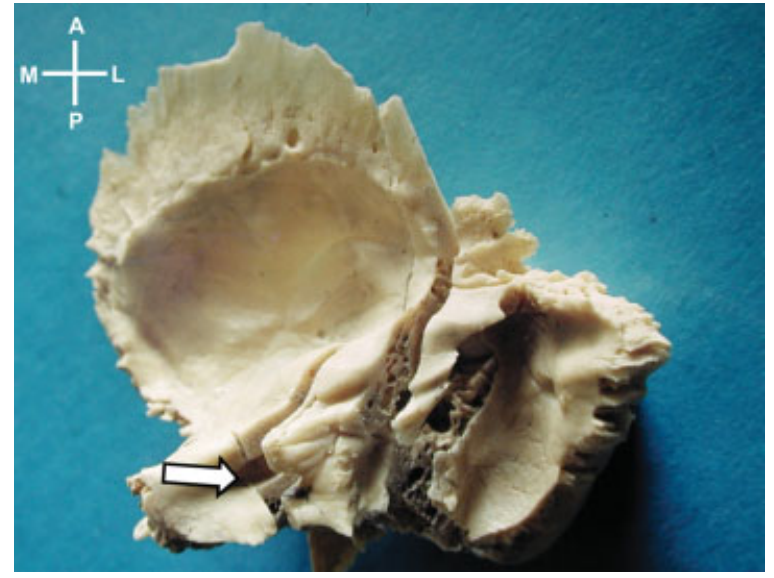

Fig. 13 Preparado anatómico. Vista posterior, superior y medial del hueso temporal derecho, el cual se encuentra parcialmente disecado. Se demarca la entrada al conducto auditivo interno (flecha).

incluyendo diversos tópicos como: Anatomía macroscópica, Histología, Patología, Antropología, Educación, Historia y Arte. En 1884 propuso la existencia de tejido linfático rodeando las aperturas nasales, orales y la faringe, con mayores concentraciones de ese tejido en las amígdalas faríngeas y palatina; hoy conocido como anillo de Waldeyer (-Figs. 17 y 18).

También describió otras estructuras: la lámina o vaina de Waldeyer (lámina fibrovascular que rodea el segmento intramural del uréter), la fascia de Waldeyer (o fascia perirrectal), la fosa de Waldeyer (un saco peritoneal inconstante por debajo de la arteria mesentérica superior) y la zona marginal de Waldeyer (sector apical del asta posterior de la sustancia gris medular). ${ }^{19}$

\section{Thomas Wharton (1614-1673) ${ }^{20}$}

Thomas Wharton (-Fig. 19) nació el 31 de agosto de 1614 en Winston-on-Tees, Inglaterra en el seno de una familia bien establecida. Hijo de John y Elizabeth Hodson, atravesó una infancia rodeada de disturbios civiles, políticos y religiosos en Inglaterra. Recibió su título de médico de la Universidad de Oxford en 1647. En 1650 fue nombrado miembro del Colegio Real de Médicos y en 1652 recibió un título honorario de la Universidad de Cambridge. Se le reconoce por haber sido uno de los médicos que permaneció en su puesto durante la Gran Plaga de 1665.

En 1656 publicó "Adenographia sive glandularum totius corporis descriptio" donde hace una detallada descripción de las glándulas del cuerpo humano. En ese libro, describe al conducto de la glándula submandibular (o conducto de Wharton) y a la sustancia gelatinosa que integra y protege al cordón umbilical (o gelatina de Wharton), rica en mucopolisacáridos (-Figs. 20 y 21).21

Wharton también se interesó por la Filosofía y por las Artes, en especial, la poesía. Se casó con Jane Aldridge y tuvo tres hijos, dos de los cuales murieron en su infancia. Su otro hijo, Thomas, siguió los pasos de su padre convirtiéndose en

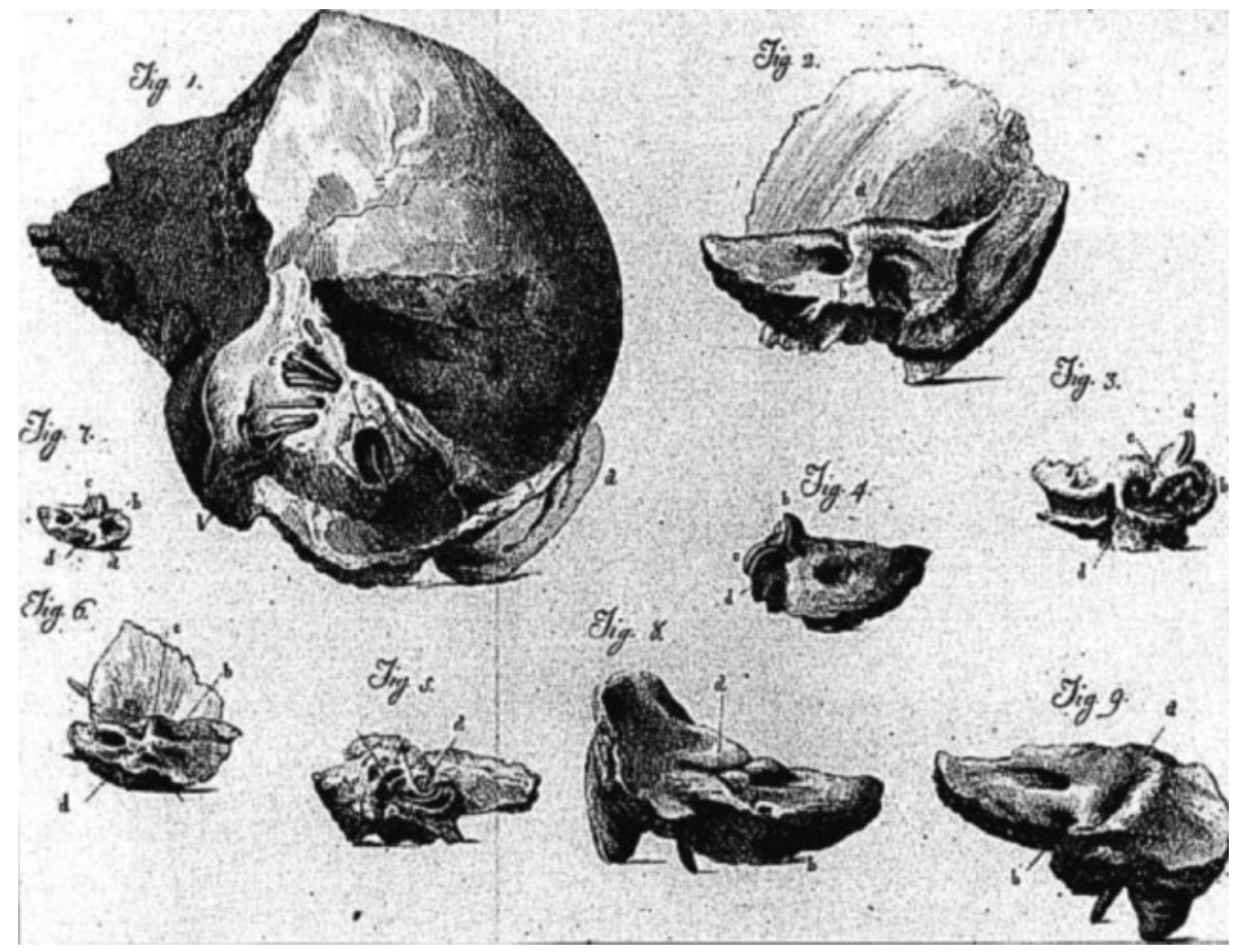

Fig. 14 Ilustración del artículo original de Mondini. La disección efectuada por Mondini muestra la fusión de los giros medio y apical de la cóclea y el ensanchamiento del acueducto vestibular. 


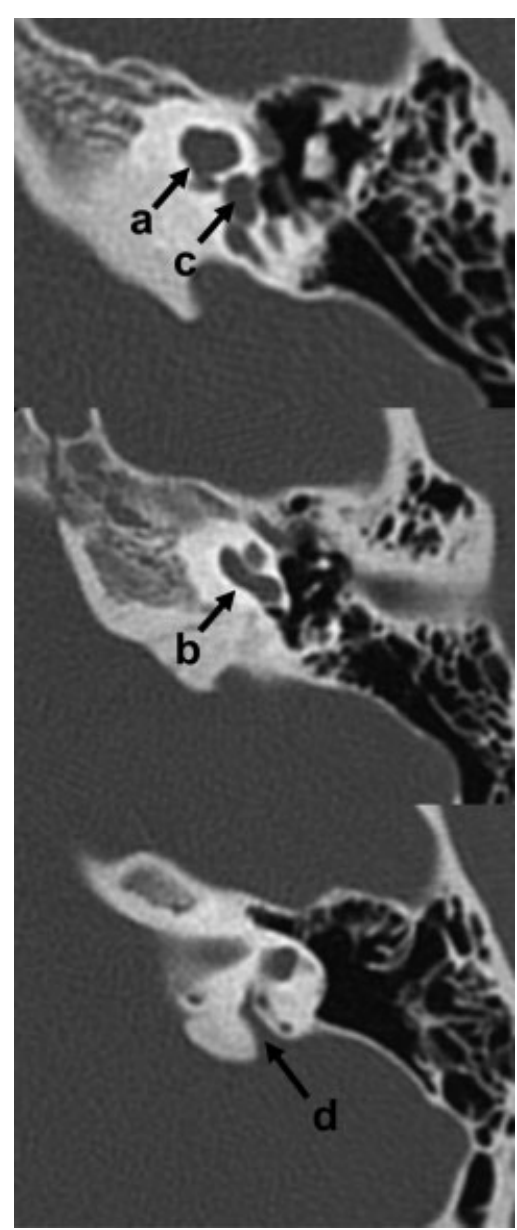

Fig. 15 Cortes axiales de tomografía computada (TC) del hueso temporal izquierdo. Paciente con hipoacusia neurosensorial bilateral congénita. Se observó fusión de los giros apical y medio de la cóclea (a) con conservación del giro basal (b). Nótese también la presencia de dilatación del vestíbulo (c) y acueducto vestibular (d).

médico. Murió el 15 de noviembre de 1673 y fue enterrado en la iglesia de Saint Michael en Londres.

\section{Niels Stensen/Nicolas Stenon (1638-1686) $)^{22,23}$}

Niels Stensen ( - Fig. 22) nació en Copenhague, Dinamarca en 1638. Durante sus estudios médicos latinizó su nombre al de Nicolai Stenonis. Sin embargo, en varios documentos, su nombre puede verse escrito como Nicolaus Stenonis, Nicolas Stenon o Niccolo Stenone. Estuvo muy involucrado en la investigación anatómica durante su carrera. Finalizó sus estudios en la Universidad de Leiden, Holanda.

En 1664 se traslada a Francia donde continúa su investigación anatómica y comienza a realizar demostraciones de disecciones, no sólo dentro del ámbito médico, sino también para el público general, cobrando una admisión. El descubrimiento del conducto de la glándula parótida (o conducto de Stensen/Stenon) ocurrió en 1660 durante su estadía en Ámsterdam, y fue una casualidad. Stensen había comprado una cabeza de oveja y su intención era disecar el cerebro del animal. Sin embargo, decidió expandir la disección a otras regiones. El 22 de abril de 1661, le escribió

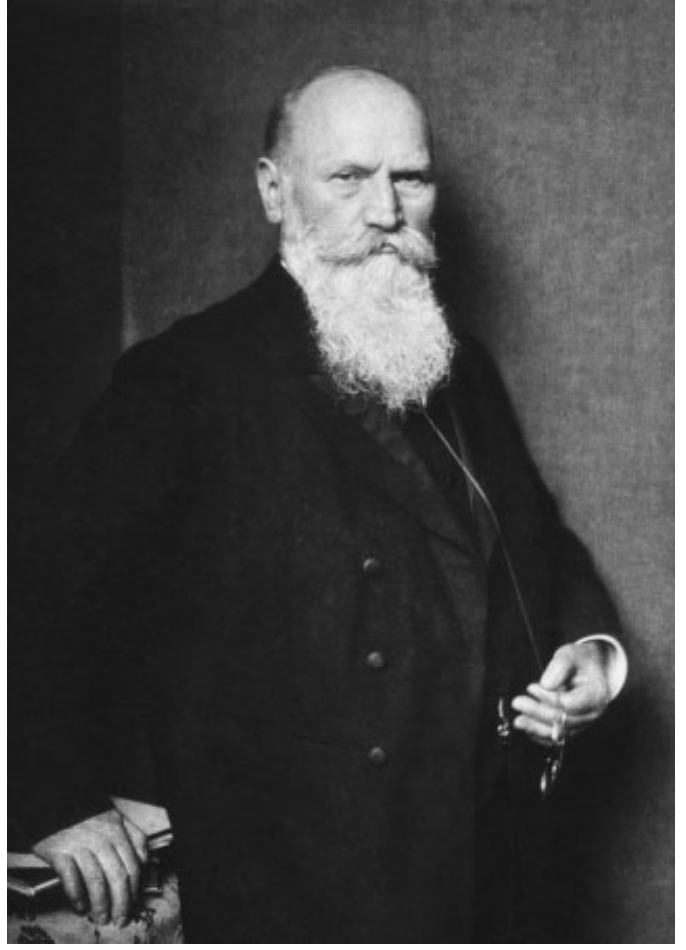

Fig. 16 Retrato de Wilhelm Waldeyer.

una carta a Thomas Wharton donde le contaba sobre su descubrimiento del conducto parotídeo (- Figs. 23 y 24).

Tempranamente en su carrera, realizó una extensa descripción de las glándulas y linfáticos de la cabeza. Fue Stensen quien realizó la primera descripción de la malformación cardiovascular que hoy conocemos como tetralogía de Fallot. También fue él quien descubrió los folículos ováricos, pero su amigo y colega Reiner de Graaf publicó su descripción previamente.

\section{Marie-Francois Xavier Bichat (1771-1802) 24,25}

Marie-Francois Xavier Bichat (-Fig. 25) fue un prominente anatomista francés en tiempos de revolución y fue uno de los fundadores de la Medicina científica en Francia. Condujo diversos estudios experimentales, los cuales sentaron las bases para el desarrollo de la fisiología moderna. Basado en los hallazgos de autopsias, Bichat introdujo 21 tipos de tejido como elementos básicos de todos los órganos. Su nombre es recordado por varios epónimos de la Medicina como por ejemplo la fosa de Bichat (fosa pterigopalatina) y la bola de Bichat (cuerpo adiposo del espacio bucal) (-Figs. 26 y 27).

\section{Conclusión}

El uso de epónimos es frecuente en la Anatomía y Radiología de la cabeza y el cuello. Creemos que el conocimiento de ellos y de las causas que llevaron a su surgimiento, pueden ser recursos que faciliten la memorización de reparos anatomoradiológicos importantes. Consideramos no menos importante también, homenajear a esos individuos históricos de la Medicina. 


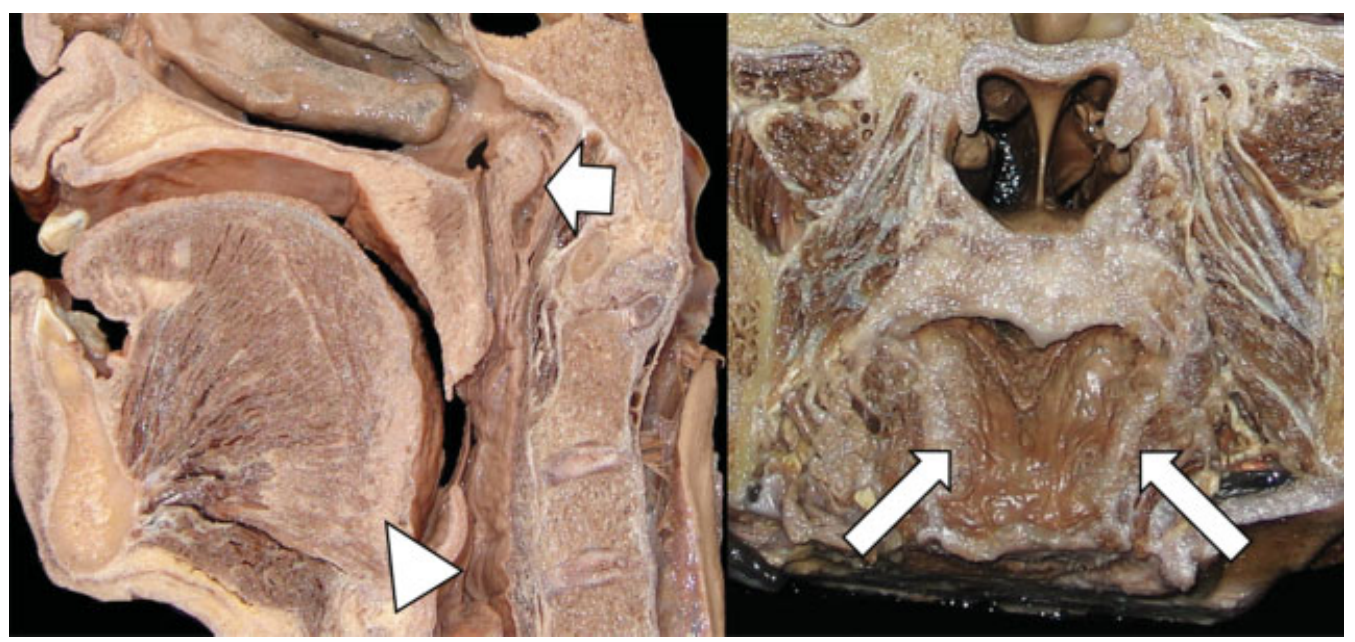

Fig. 17 Preparado anatómico. Cortes sagital y coronal mostrando las estructuras del anillo de Waldeyer. Se demarcan las principales estructuras que conforman el anillo de Waldeyer: amígdalas palatinas (flechas largas), amígdalas faríngeas o adenoides (flecha corta) y amígdalas linguales (cabeza de flecha).

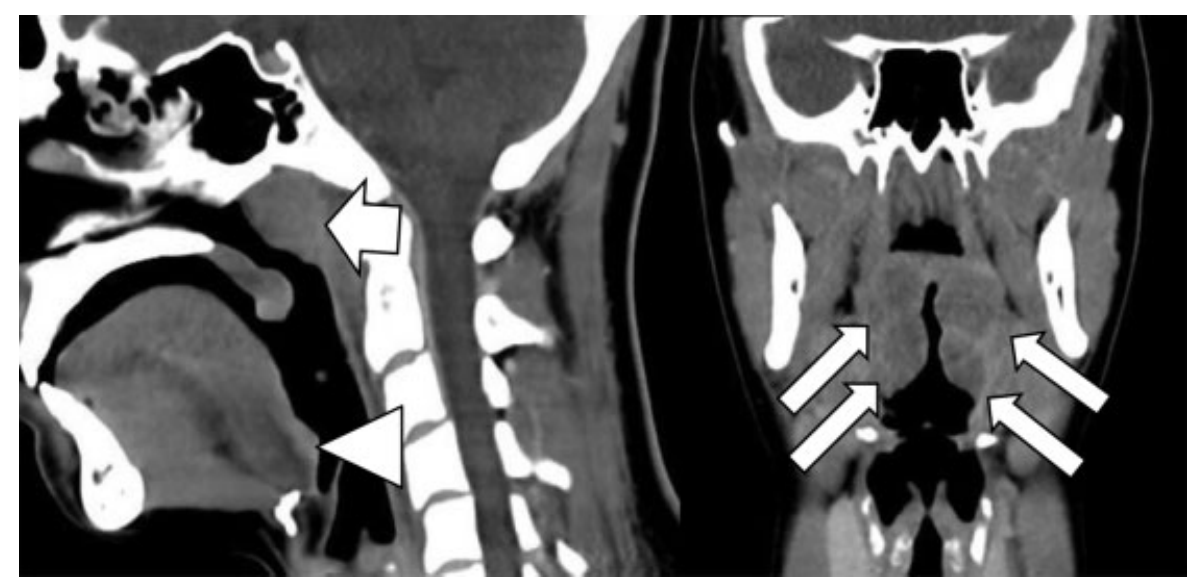

Fig. 18 Cortes sagital y coronal de TC de la faringe. Paciente de 16 años asintomática. Se demarca la hipertrofia fisiológica de las principales estructuras que conforman el anillo de Waldeyer: amígdalas palatinas (flechas largas), amígdalas faríngeas o adenoides (flecha corta) y amígdalas linguales (cabeza de flecha).

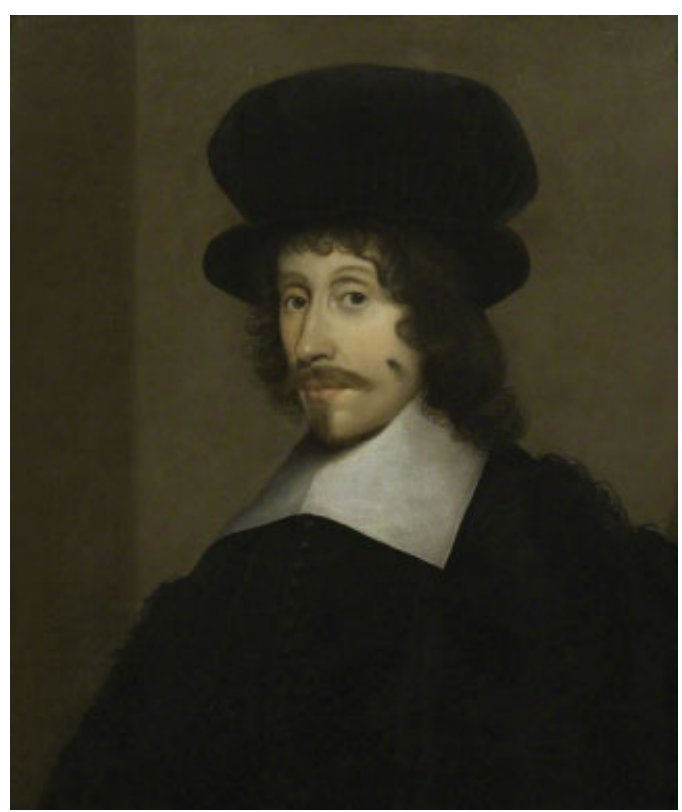

Fig. 19 Retrato de Thomas Wharton.

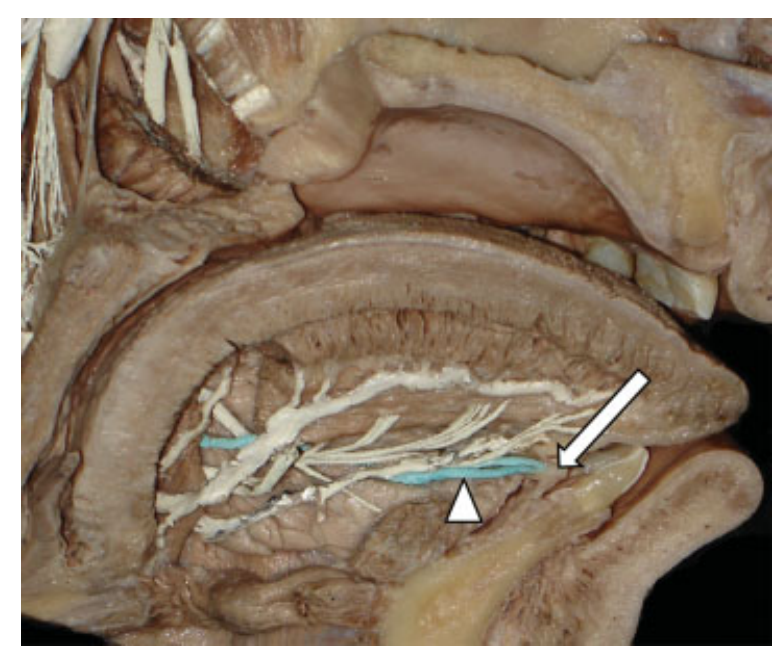

Fig. 20 Preparado anatómico. Vista medial de la cavidad oral y piso de la boca. Se muestra el trayecto del conducto de Wharton izquierdo (coloreado en celeste), en el piso de la boca que termina en el orificio umbilical homolateral (flecha larga). Nótese la existencia del conducto sublingual mayor (cabeza de flecha), acompañándolo en su sector distal. Reimpreso con el permiso del editor. Copyright@ 2016 Fronteras de Medicina. Todos los derechos reservados. 

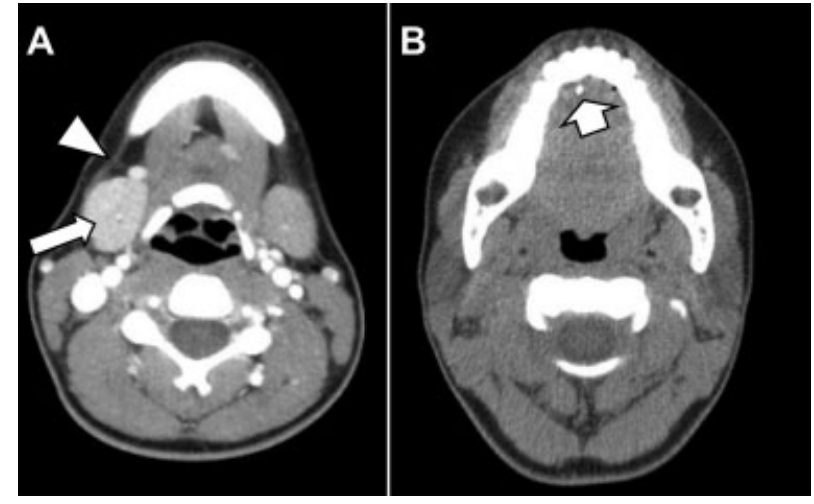

Fig. 21 Cortes axiales de TC a la altura del piso de la boca. Paciente que consultó por dolor e hinchazón en región submandibular que se exacerba con la salivación. En el corte inferior de la adquisición postcontraste endovenoso (A) se señala el realce asimétrico de la glándula submandibular derecha (flecha larga) respecto a su contralateral. Existe también un ligero engrosamiento de la fascia cervical superficial adyacente (cabeza de flecha). En el corte superior de la adquisición pre-contraste endovenoso (B) se observó la existencia de un lito en el sector distal del conducto submandibular, a nivel de la carúncula salivar (flecha corta). Dichos hallazgos se atribuyen a sialoadenitis aguda. Reimpreso con el permiso del editor. Copyright $\odot$ 2016 Fronteras de Medicina. Todos los derechos reservados.

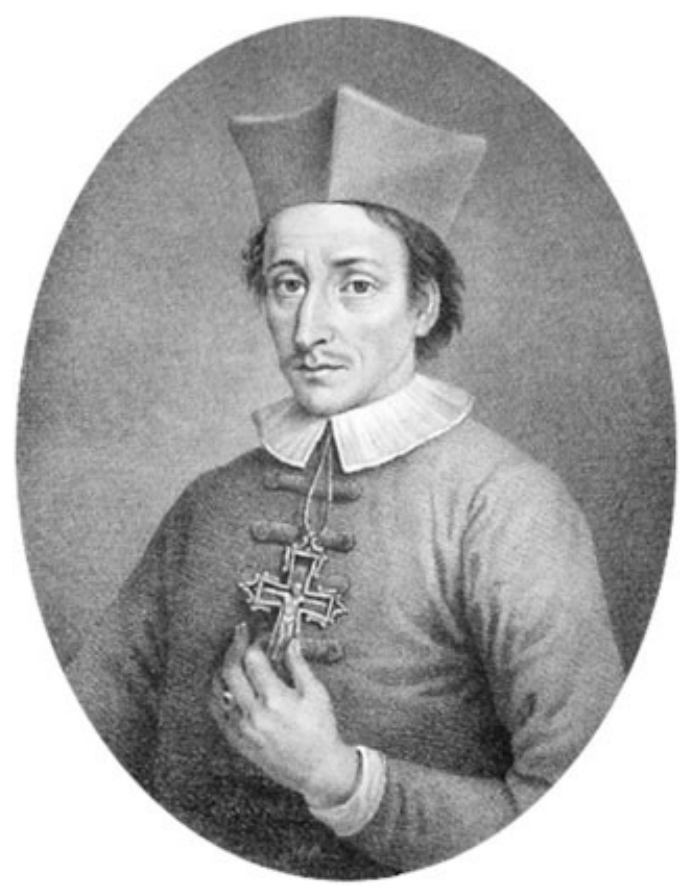

Fig. 22 Retrato de Niels Stensen/Nicolas Stenon.

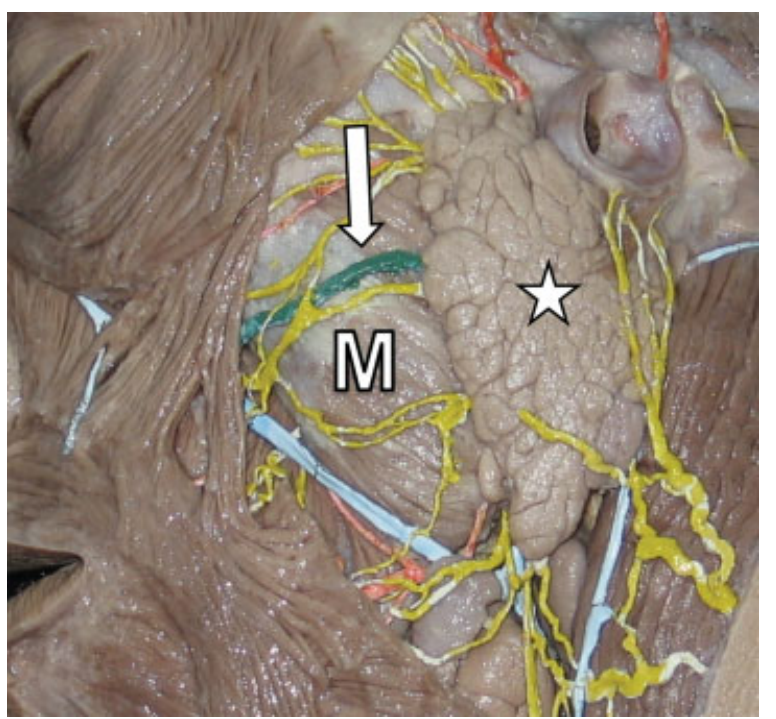

Fig. 23 Preparado anatómico de la hemicara izquierda. Se observa el trayecto del conducto de Stenon coloreado en verde (flecha) en los planos profundos de la cara, emergiendo de la glándula parótida (estrella) y en contacto con el músculo masetero (M). Coloreado en amarillo se observan los ramos del nervio facial y en rojo, las divisiones de la arteria temporal superficial.

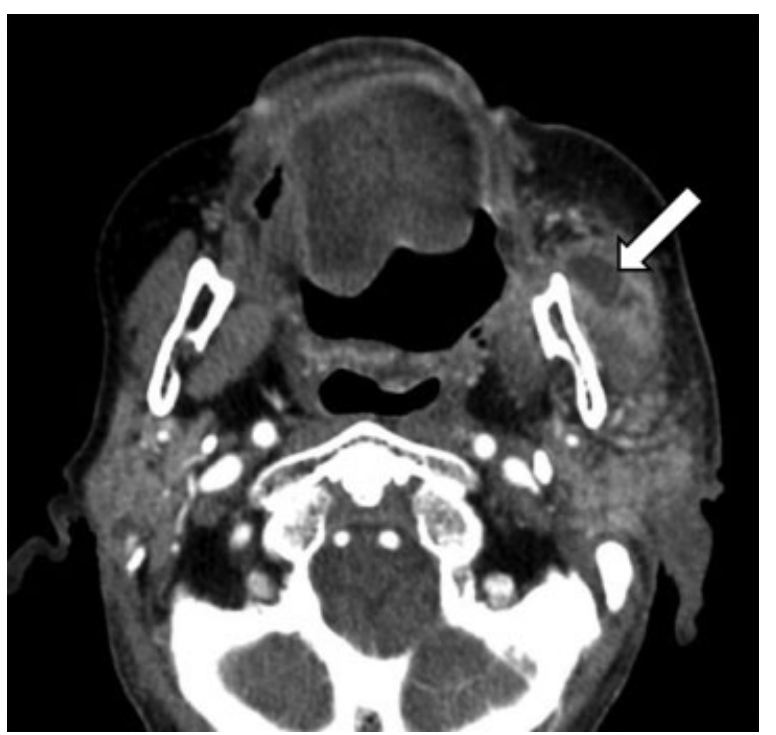

Fig. 24 Corte axial de TC con contraste endovenoso. Paciente con fiebre y dolor en región parotídea izquierda. Se señala con una flecha una imagen ovoidea, irregular, que muestra realce predominantemente periférico tras administrar contraste endovenoso, atribuible a absceso del conducto de Stenon. 


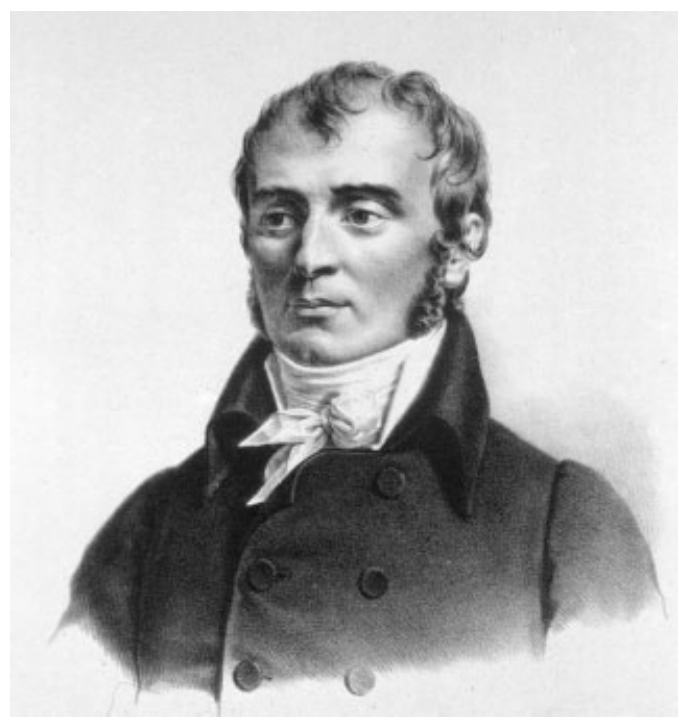

Fig. 25 Retrato de Marie-Francois Xavier Bichat.

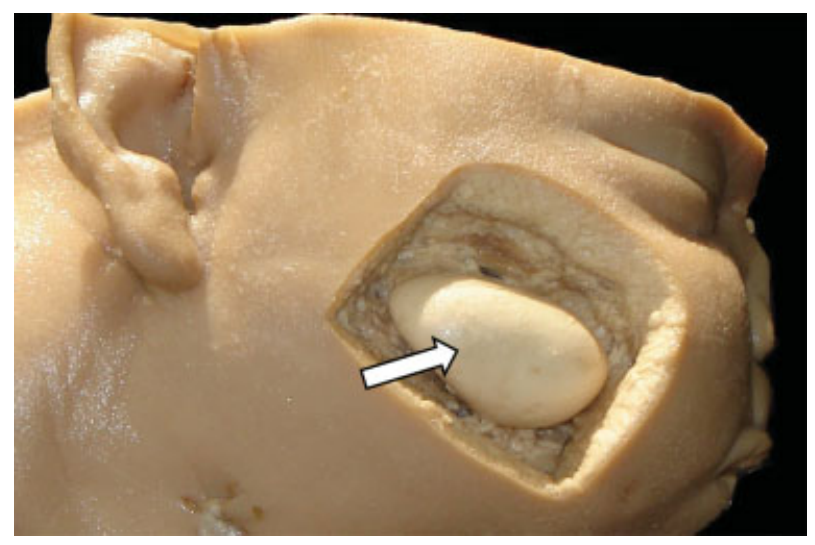

Fig. 26 Preparado anatómico de la hemicara derecha. La imagen corresponde a una disección de la hemicara derecha destacando la bola de Bichat en los planos profundos.

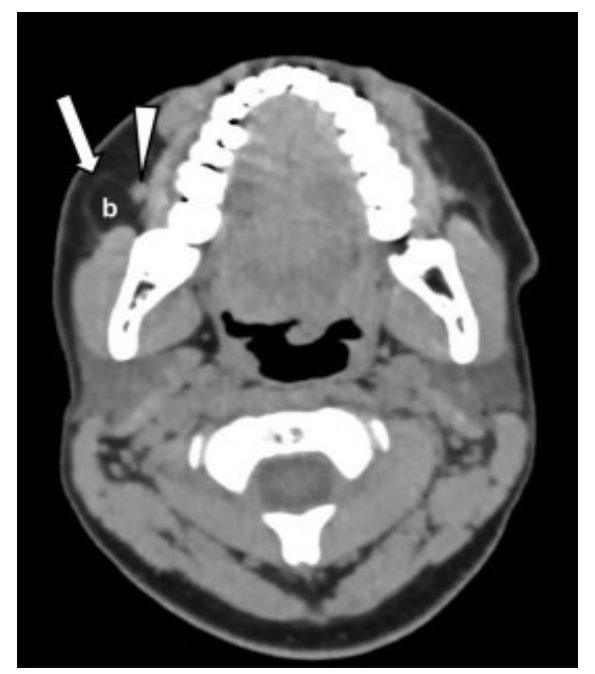

Fig. 27 Corte axial de TC sin contraste endovenoso. Niño de 12 años de edad, que consultó por cefalea persistente, refiriendo también que se palpa un bulto en la hemicara derecha. Nótese la existencia de grasa prominente en topografía de la bola de Bichat (b), que desplaza la fascia cervical superficial (flecha) y el conducto de Stenon (cabeza de flecha) derechos. Ese hallazgo corresponde a un lipoma de la bola de Bichat. El conducto de Stenon se observa en forma parcial.
Confidencialidad de los datos

Los autores declaran que han seguido los protocolos de su centro de trabajo sobre la publicación de datos de pacientes y que todos los pacientes incluidos en el estudio han recibido información suficiente y han dado su consentimiento informado por escrito.

\section{Conflicto de intereses}

Los autores declaran no tener ningún conflicto de intereses, excepto los Dres. Chaves y Miquelini que declaran, como posible conflicto de interés, ser consultores de la RAR.

\section{Agradecimientos}

Al Prof. Dr. Horacio Conesa (1944-2015), mentor y maestro de anatomía, pilar fundamental en el desarrollo de la neuroanatomía en la Universidad de Buenos Aires. Martín Fernando Ferraro agradece al Prof. Dr. Conesa por la cesión de las imágenes de preparados anatómicos durante su labor en el Laboratorio de Neuroanatomía del Instituto de Morfología Juan José Naón. A la Dra. Lucía Tomassi, por su incansable labor en la formación de ayudantes de anatomía en la Universidad de Buenos Aires y su constante estimulación al conocimiento de la historia de la medicina.

\section{Bibliografía}

1 Real Academia Española. Diccionario de la lengua española. RAE website. Disponible en: http://dle.rae.es">http://dle.rae.es. (accedido Abril 2018

2 Ferguson RP, Thomas D. Medical eponyms. J Community Hosp Intern Med Perspect 2014;4(04):3

3 Thomas PB. Are medical eponyms really dying out? A study of their usage in the historical biomedical literature. J R Coll Physicians Edinb 2016;46(04):295-299

4 Woywodt A, Matteson E. Should eponyms be abandoned? Yes. BMJ 2007;335(7617):424

5 Whitworth JA. Should eponyms be abandoned? No. BMJ 2007; 335(7617):425

6 Bunch PM. Anatomic Eponyms in Neuroradiology: Head and Neck. Acad Radiol 2016;23(10):1319-1332

7 Ferraro FM, García A, Mukherji SK. Nombres históricos en anatomía y radiología de cabeza y cuello. Front Med 2016;11 (04):114-118

8 Amene C, Cosetti M, Ambekar S, Guthikonda B, Nanda A. Johann Christian Rosenmüller (1771-1820): A Historical Perspective on the Man behind the Fossa. J Neurol Surg B Skull Base 2013;74(04): 187-193

9 Rosenmüller JC. Handbuch der Anatomie: nachLebersUmriss der Zergliederungskunst zum Gebrauch der Vorlesungen. Leipzig: Koehler; 1808

10 van Gijn J. Charles Bell (1774-1842). J Neurol 2011;258(06): $1189-1190$

11 Bell C. On the Nerves; Giving an Account of Some Experiments on Their Structure and Functions, Which Lead to a New Arrangement of the System. Philos Trans R Soc Lond 1821;111:398-424

12 Kshettry VR, Lee JH, Ammirati M. The Dorello canal: historical development, controversies in microsurgical anatomy, and clinical implications. Neurosurg Focus 2013;34(03):E4

13 Dorello P. Considerazioni sopra la causa della paralisi transitoria dell' abducent en elle flogosi dell' orecchio medio. En: Ferreri G, ed. Atti della Clinica Oto-Rino-Laringoiatrica. Roma1905:209-217 
14 Ambekar S, Sonig A, Nanda A. Dorello's Canal and Gruber's Ligament: Historical Perspective. J Neurol Surg B Skull Base 2012;73(06):430-433

15 Destrieux C, Velut S, Kakou MK, Lefrancq T, Arbeille B, Santini JJ. A new concept in Dorello's canal microanatomy: the petroclival venous confluence. J Neurosurg 1997;87(01):67-72

16 Paparella MM. Mondini's deafness. A review of histopathology. Ann Otol Rhinol Laryngol Suppl 1980;89(2 Pt 3):1-10

17 Mondini C. Minor works of Carlo Mondini: the anatomical section of a boy born deaf. Am J Otol 1997;18(03):288-293

18 Winkelmann A. Wilhelm von Waldeyer-Hartz (1836-1921): an anatomist who left his mark. Clin Anat 2007;20(03):231-234

19 Beuls E, Gelan J, Vandersteen M, Adriaensens P, Vanormelingen L, Palmers Y. Microanatomy of the excised human spinal cord and the cervicomedullary junction examined with high-resolution MR imaging at 9.4 Tesla. AJNR Am J Neuroradiol 1993;14(03):699-707
20 Wells WA. Thomas Wharton, [1614-1673,] first gland specialist and discoverer of a salivary duct. Laryngoscope 1948;58(03): 254-266

21 Moshiri M, Zaidi SF, Robinson TJ, et al. Comprehensive imaging review of abnormalities of the umbilical cord. Radiographics 2014;34(01):179-196

22 Strkalj G. Niels Stensen and the Discovery of the Parotid Duct. Int J Morphol 2013;31(04):1491-1497

23 Noguera Paláu JJ. [Niels Stensen. Copenhagen, 1638 - Schwerin, 1686]. Arch Soc Esp Oftalmol 2009;84(04):223-224

24 Pérez Perales JE. Marie-François Xavier Bichat y el nacimiento del método anatomoclínico. Cir Gen 2011;33:54-57

25 Shoja MM, Tubbs RS, Loukas M, Shokouhi G, Ardalan MR. MarieFrançois Xavier Bichat (1771-1802) and his contributions to the foundations of pathological anatomy and modern medicine. Ann Anat 2008;190(05):413-420 